\title{
Vibrational Analysis of Disc Brake Rotor of a Two Wheeler to find the defect using FEA
}

\author{
D. Bhadgaonkar, A. Singh, S. S. Jadhav, S. S. Jadhav \\ (Department of Mechanical Engineering, M. E. S. College of Engineering, S. P. Pune University, India)
}

\begin{abstract}
The current tendencies in automotive industry need intensive investigation in problems of interaction of active safety systems with brake system equipment. Disc brakes use a flat, disc-shaped metal rotor that spins with the wheel. When the brakes are applied, a caliper squeezes the brake pads against the disc, slowing the wheel. The main motive is to Finding the difference in frequency curve of the disc brake rotor by artificially creating a crack in the disc brake rotor. By using Finite Element Analysis and developing an equation between natural frequency and crack depth. This equation can be used to predict or identify the crack depth on disc
\end{abstract}

Keywords: Crack Generation, Disc Brake Rotor, FEA, Frequency Response Curve, Modal Analysis, Natural Frequency, Vibrational Analysis.

\section{Introduction}

A brake is a mechanical device which inhibits motion. Most commonly brakes use friction to convert kinetic energy into heat. Brakes are generally applied to rotating axles or wheels, but may also take other forms such as the surface of a moving fluid.

\subsection{Working of a Disc Brakes System}

\section{How A Disc Brake Works}

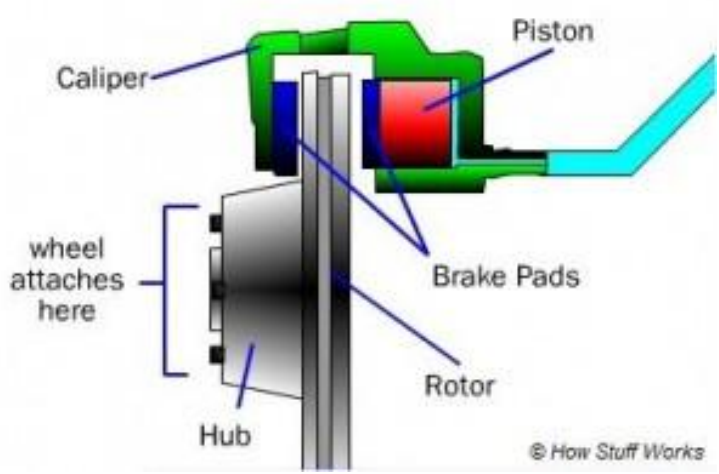

Fig. 1: Working of Disc brake

On applying the brake lever, the vehicle slows or stops. A brake system is designed to slow and halt the motion of vehicle. To do this, various components within the brake system must convert vehicle's moving energy into heat. This is done by using friction. Friction is the resistance to movement exerted by two objects on each other. Two forms of friction play a part in controlling a vehicle: Kinetic or moving, and static or stationary. The amount of friction or resistance to movement depends upon the type of material in contact, the smoothness of their rubbing surfaces and the pressure holding them together. Thus, in a nutshell any vehicles' brake works by applying a static surface to a moving surface of a vehicle, thus causing friction and converting kinetic energy into heat energy. As the brakes on a moving automobile are put into motion, rough-textures brake pads or brake shoes are pressed against the rotating parts of vehicle, be it disc or drum. The kinetic energy or momentum of the vehicle is then converted into heat energy by kinetic friction of the rubbing surfaces and the vehicle slows down. When vehicle comes to stop, it is held in place by static friction. The friction between surfaces of brakes as well as the friction between tires and roads resists any movement. To overcome the static friction that holds the vehicle motionless, brakes are released. The heat energy of combustion of in engine is converted into kinetic energy by transmission and drive train, and the vehicle moves. [2] 


\subsection{Problems in Disc Brake}

\subsubsection{Scarring}

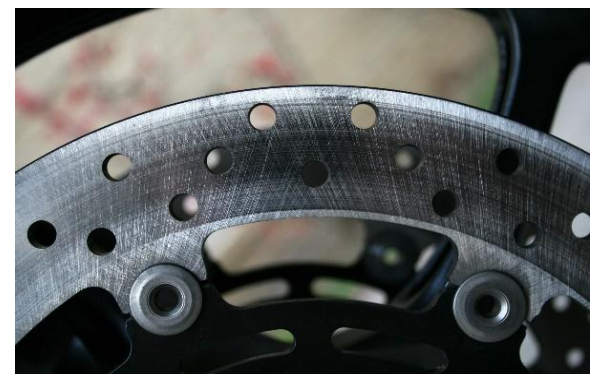

Fig. 2: Scarring

Scarring can occur if brake pads are not changed promptly when they reach the end of their service life and are considered worn out. To prevent scarring, it is prudent to periodically inspect the brake pads for wear.

\subsubsection{Cracking}

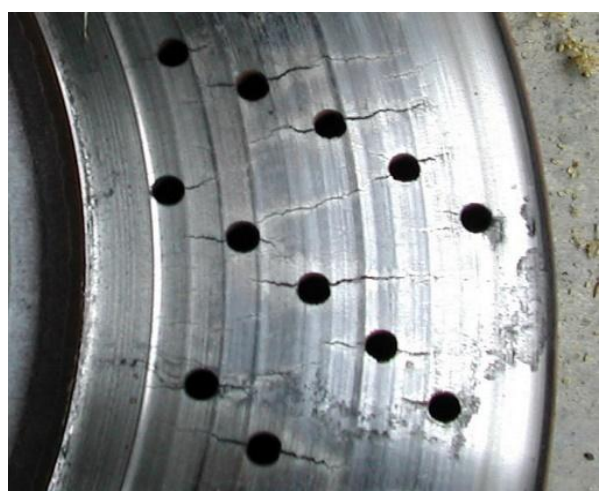

Fig. 3: Cracking

Cracking is limited mostly to drilled discs, which may develop small cracks around edges of holes drilled near the edge of the disc due to the disc's uneven rate of expansion in severe duty environments. A brake disc is a heat sink, but the loss of heat sink mass may be balanced by increased surface area to radiate away heat. Small hairline cracks may appear in any cross drilled metal disc as a normal wear mechanism, but in the severe case the disc will fail catastrophically. No repair is possible for the cracks, and if cracking becomes severe, the disc must be replaced.

\subsubsection{Rusting}

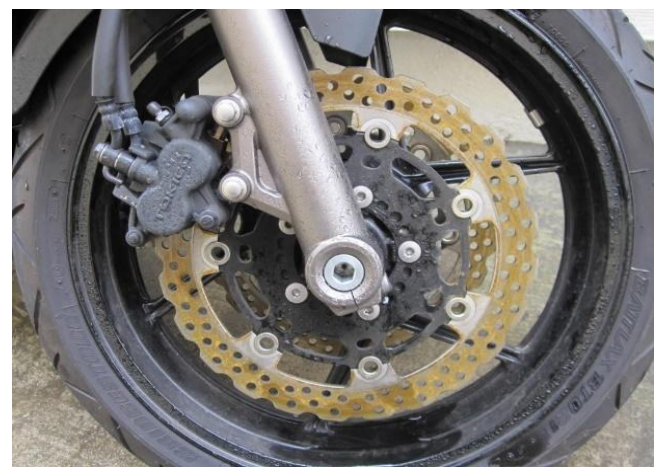

Fig. 4: Rusting

The discs are commonly made from cast iron and a certain amount of what is known as "surface rust" is normal. The disc contact area for the brake pads will be kept clean by regular use, but a vehicle that is stored for an extended period can develop significant rust in the contact area that may reduce braking power for a time until the rusted layer is worn off again. Over time, vented brake discs may develop severe rust corrosion inside the ventilation slots, compromising the strength of the structure and needing replacement. 


\section{Vibrational or Modal Analysis}

In modal testing, frequency response function measurements are usually made under controlled conditions, where the test structure is artificially excited by using either an impact hammer or one or more shakers driven by broadband signals. A multi-channel FFT analyzer is then used to make FRF measurements between input and output DOF pairs on the test structure. Modal analysis is the process of determining the modal parameters of a structure for all modes in the frequency range of interest. Modal analysis is nothing but one of the method for finding the modes of vibration of structure or machine. In other words it is used to find out the dynamic characteristic of a system in form of natural frequency and mode shapes. If we understand better on natural frequency and mode of vibration we can easily understand noise and vibration problem.

Modes (or resonances) are inherent properties of a structure. Resonances are determined by the material properties (mass, stiffness and damping properties) and boundary conditions of structure. Each mode is defined by natural (modal or resonant) frequency, modal damping and a mode shape. If either the material properties or the boundary conditions of structure change, its modes will change. For instance, if mass is added to vertical pump it will vibrate differently because its modes have changed. The disc of a brake rotor is tested through the Modal Analysis with free - free boundary conditions.

Natural frequency of any object depends on the shape of that object, if there is any defect like a crack in the disc break rotor then the frequency vs. mode shape curve for defective rotor must deviate from that of the undamaged rotor. This deviation can be used as an indication of the defect in rotor. In this work modal analysis of undamaged and damaged (i.e. cracked) disc brake rotor is carried out to develop the relation between the natural frequency and the crack depth.

\subsection{Modeling Using CATIA}

The disc of a brake assembly is first modeled in CATIA which is excellent CAD software, which makes modeling so easy and user friendly. A crack is generated on the lateral surface of the disc brake rotor as shown in the figure 6 .

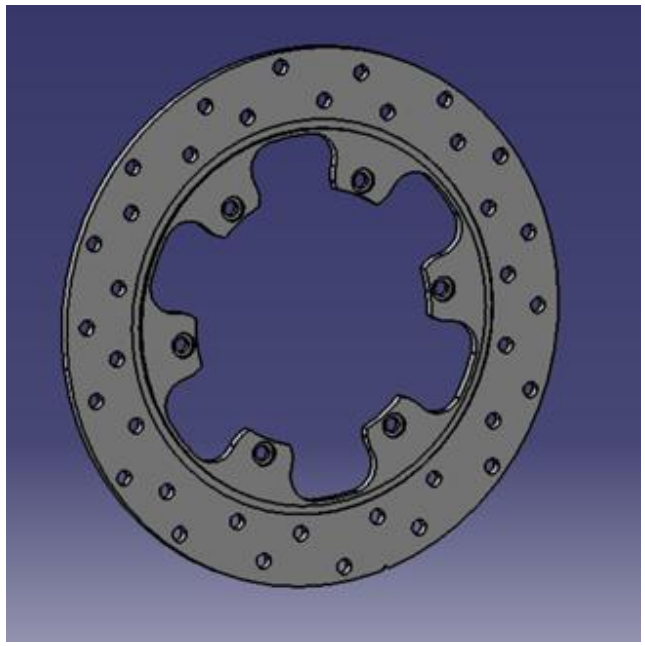

Fig. 5: Uncracked Rotor

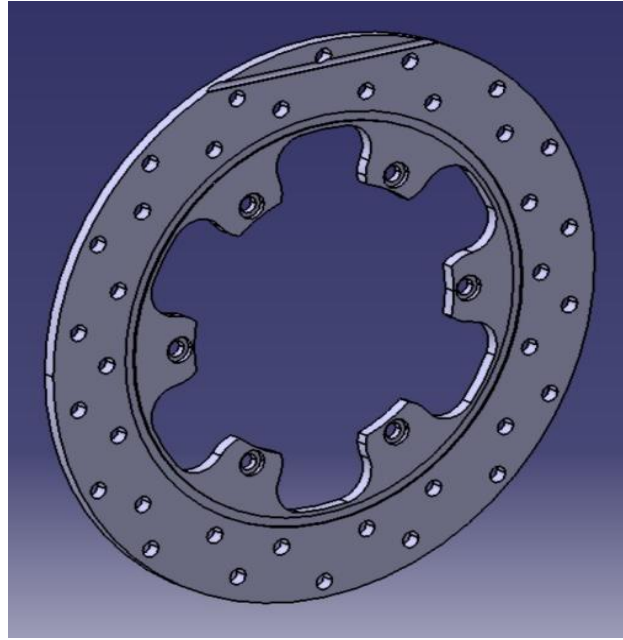

Fig. 6: Cracked Rotor

\subsection{Finite element analysis of disc break rotor}

The model is then transferred to .Step format and exported to analysis software ANSYS 14.5. after that the disc of a brake assembly is analyzed. Pre-processing is first step which involves modeling, geometric clean up, element property definition and meshing. Next step includes solution of problem, which involves imposing boundary conditions on the model and then solution runs. Next in sequence is post processing, which involves analyzing the natural frequency for different mode of vibration.

\section{Results And Discussions:}

The following result has been tabulated after the analysis on ANSYS for different crack depths. Images of three mode shapes for each crack depth are given below. From the obtained data, graph is plotted and the relationship between crack depth and frequency response curve is deduced. This relation can be used to predict or identify the crack depth on disc.

The final equation deduced is:

$$
y=296.06 x^{-0.005} \text { (Where Y is Natural frequency and X is Crack depth) }
$$


Table1: Results of FEA analysis

\begin{tabular}{|c|c|c|c|c|c|}
\hline & \multicolumn{5}{|c|}{ Mode } \\
\hline & 1 & 2 & 3 & 4 & 5 \\
\hline Frequency for Uncracked & 296.14 & 296.65 & 694.29 & 805 & 839 \\
\hline Frequency for Cracked 1mm & 294.8 & 295 & 691 & 800 & 835 \\
\hline Frequency for Cracked 2mm & 294.65 & 294.91 & 691 & 800 & 833 \\
\hline Frequency for Cracked 3mm & 294 & 295 & 691 & 801 & 832 \\
\hline
\end{tabular}

\section{Without Crack:}

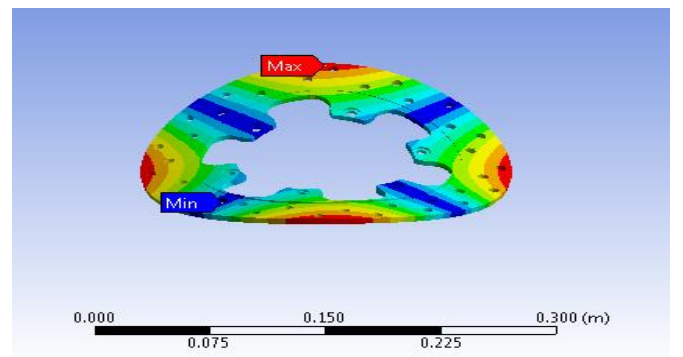

Fig. 7: Mode Shape 1

$1 \mathrm{~mm}$ Crack Depth-

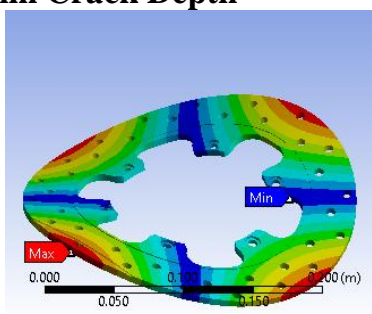

Fig. 8: Mode Shape 1

\section{2mm Crack Depth-}

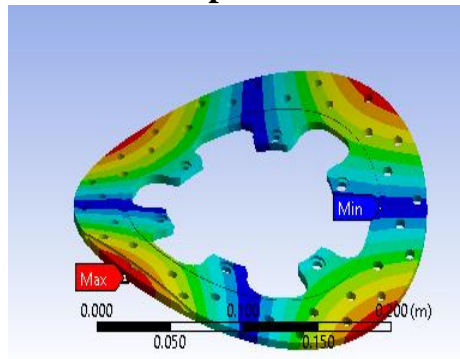

Fig. 11: Mode Shape 1

\section{3mm Crack Depth-}

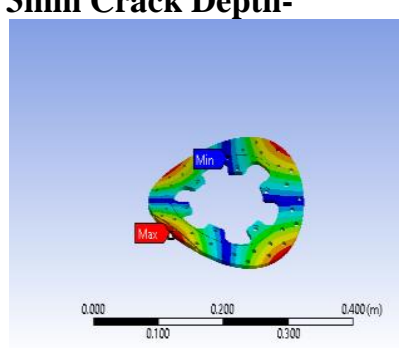

Fig. 14: Mode Shape 1

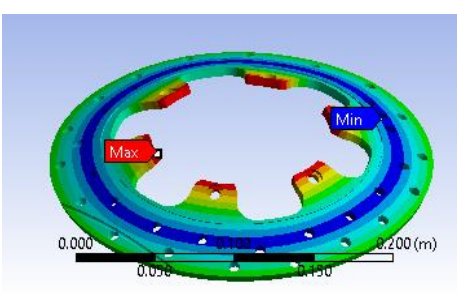

Fig. 9: Mode Shape 2

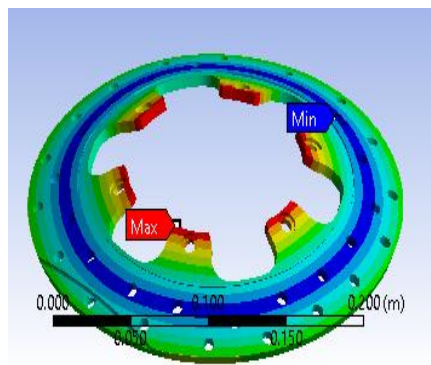

Fig. 12: Mode Shape 2

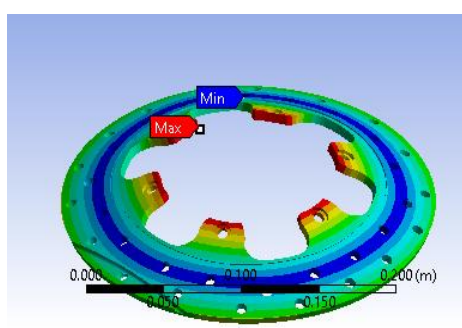

Fig. 15: Mode Shape 2

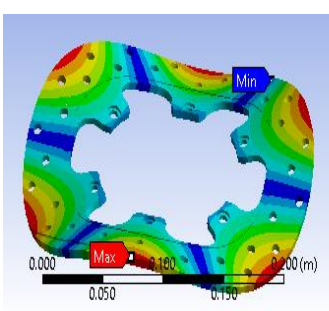

Fig. 10: Mode Shape 3

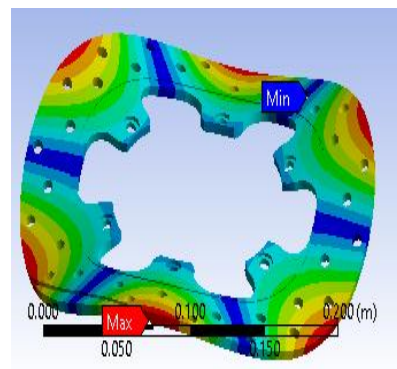

Fig. 13: Mode Shape 3

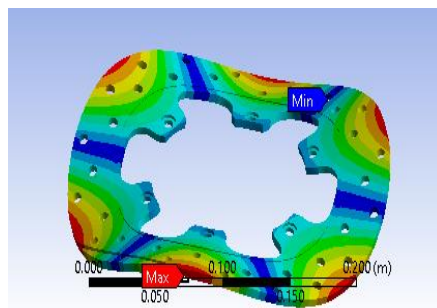

Fig. 16: Mode Shape 3 


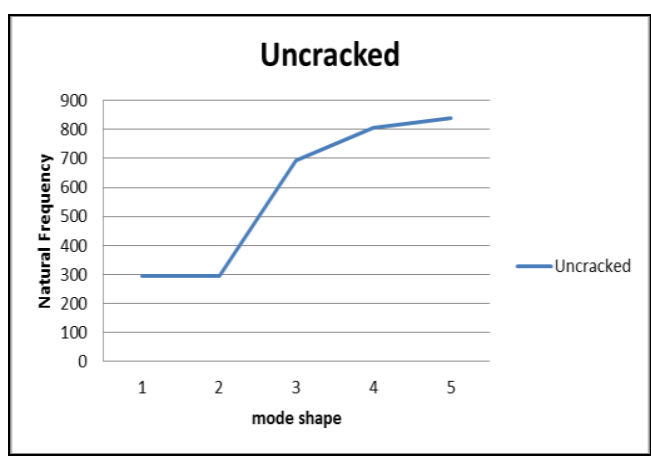

Fig. 17: Mode Shape VS. Natural frequency for undamaged disc

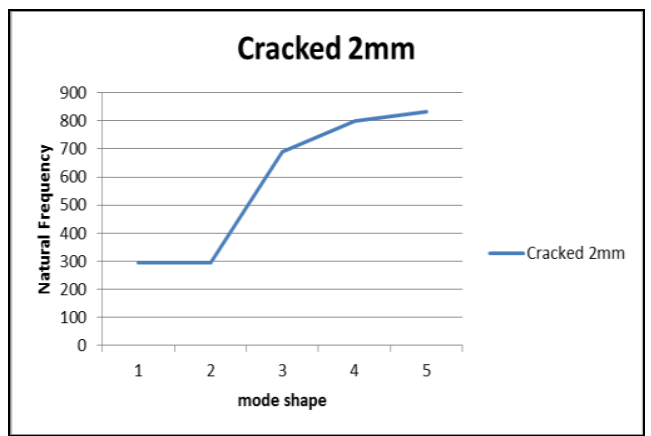

Fig. 19: Mode Shape VS. Natural frequency for $2 \mathrm{~mm}$ crack depth

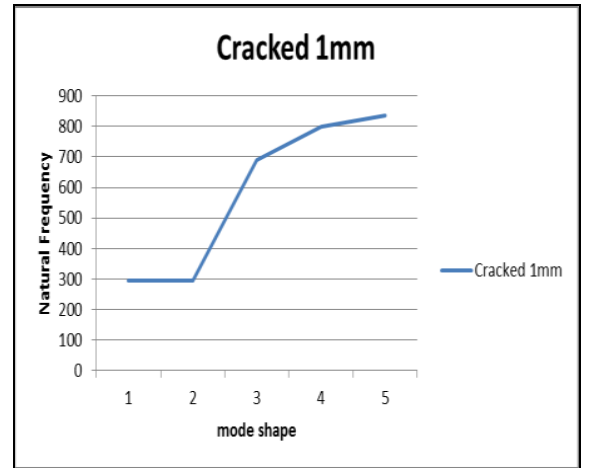

Fig. 18: Mode Shape VS. Natural frequency for $1 \mathrm{~mm}$ crack depth

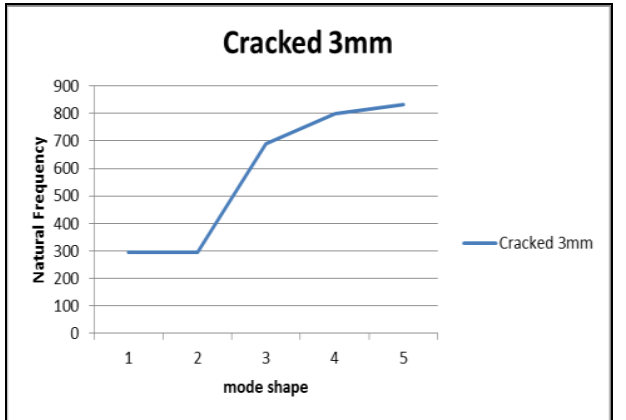

Fig. 20: Mode Shape VS. Natural frequency for $3 \mathrm{~mm}$ crack depth

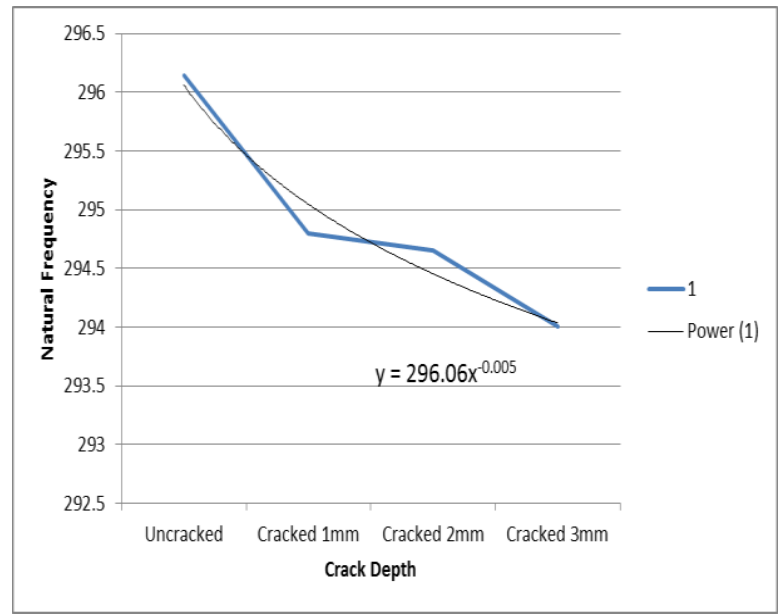

Fig. 20: Crack depth VS. Natural frequency for first mode shape

\section{Conclusion}

Modal analysis is done to find out the natural frequency of the existing disc at different mode shape. Any defect like a crack on disc brake gives change in frequency curve. Natural frequency of the of cracked disc brake rotor decreases as the crack depth increases. The equation deduced will give us the direct value if we now the value of frequency or the crack depth.

\section{References}

[1] V. Kumar, P. Kumar, Manjunatha, M. D. Pawar, Shivaramakrishna, Finite Element Analysis of Two Wheeler Disc Brake Rotor, Imperial Journal of Interdisciplinary Research (IJIR), 2(7), 2016, 928-932.

[2] N. Balasubramanyam, G. Prasanthi, Design and Analysis of Disc Brake Rotor for a Two Wheeler, International Journal of Mechanical and Industrial Technology (IJMIT), 1(1), 2014, 7-12.

[3] R. Venkatramanan, S. B. Kumaragurubaran, K. C. Vishnu, Sivakumar S, Saravanan B, Design and Analysis of Disc Brake Rotor, International Journal of Applied Engineering Research 10(1), 2015, 14558-14562.

[4] Velveeta L. C, N. A. N. Rao, Design \& Analysis of a Disc Brake using FEA, International Journal of Computational Engineering Research (IJCER), 04(10)2014, 27-31.

[5] N. K. Kharate, S. S. Chaudhari, Department of Mechanical Engineering, YCCOE, Nagpur, 'Investigation of Natural 
Frequency and Modal Analysis of Brake Rotor Using FEA and EMA', International Journal of Innovative Research in Science, Engineering and Technology, 3(10),2014,16495-16500.

[6] A.Warade, V.V.Saidpatil, 'Vibration Analysis of Circular Disc with Radial Cracks', International Journal of Mechanical Engineering (SSRG-IJME), 1(3) July 2014, 1-4. 